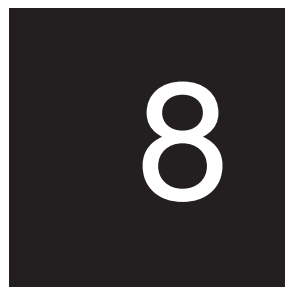

\title{
Culture and sustainable marine resource development in the Pacific
}

\section{Philipp Muller}

This chapter focuses on resource utilisation in the marine environment. I will draw largely from my own experiences, and my approach will be mainly anecdotal. It will also become obvious that I am not proposing any solutions. This is not because I think that there are no solutions. They are in fact fairly widely known, but if there is anything I have learned, it is that the solutions require action-and that is a different question.

The importance of the cultural aspects of development was brought home to me quite early in my career when it appeared that national developmental objectives were not being met. However, there were at the time enough reasons and excuses to confuse the real causes; and besides, the lessons were not easily learned. I was closely associated with efforts to improve the general well-being of our villagers by a variety of projects and programs in agriculture, forestry and fisheries. There were ever-present efforts to rehabilitate the copra, cocoa and banana export industries, which, for whatever reason, were directed towards harnessing the efforts of village smallholders. Very soon a mentality of providing incentives arose, where support was provided in bush-clearing, planting, weeding, fertilising, spraying, and whatever else was needed. Access roads, transport and centralised produce marketing soon followed. In fact, it almost 
seemed that the incentives were all set in place to prevent any sort of entrepreneurship from developing. Our planning had forgotten why villagers expended effort, and if it was for earning money, for what that money was going to be used.

In fisheries it was more boats, more outboard engines, bigger boats, bigger engines, ice plants, marketing incentives and development bank loans. At least in fisheries what remains is a thriving oceanic long-line fishery for export and a fairly effective fishing platform in the alia fishing vessels. Which is more than I can say for the banana export industry, where there is now not even a sign of a packing shed remaining.

Another early lesson I learned was that we, the educated privileged, were almost systematically desensitised to the needs of our people. Planners often neglected the needs of all the stakeholders, and at their own peril. We often enunciated noble goals such as job creation, foreign exchange earnings, improved balance of payments, and even a more equitable distribution or redistribution of wealth and involvement in development. We should have been attempting to understand motivating factors, such as family dignity, the pressure of politics, the community and the church, education, and events such as Children's Sunday and other matters of relevance to the individual and extended family. Everything was coming from a faceless government that was progressively becoming distressed by its lack of success, and being carried out by officials who were hard-pressed and under-resourced. Yet all that people wanted to know was what to produce, how to produce more, and how to get the best from markets. This brings to mind two universal lies: that you can get useful information from a government department and that a government official is out to help you.

Information (and the research that is needed to obtain such information) has generally been devoid of any consideration of how the result would be transferred to the final users, the people. The classic example is that of fisheries research in which total catch information has to be obtained, and maintained, and if overexploitation is proven, or even suspected, then some way of reducing the quantity of fishing effort has to be found. The question is then how to do this. The fishermen know their catches are declining, but any form of regulation will mean that they will be committed to defeating the controls. Surely the fishermen who are most affected must be brought into a self-regulatory position. Traditional controls such as 
fishing closure in particular seasons, timeframes or areas, are easy to self police. Research should be geared towards culturally acceptable solutions and not the other way round.

This is not to say that there have not been traditional fishing methods which have had a disastrous effect on the fish stock or their environment. These include fish-drives, fish traps and fish poisoning. In the past, the resources could generally recover with time, but now, population pressures mean that the degradation continues at an almost irreversible rate. The fishermen need to be brought into the decision-making process and to take responsibility for policing any agreed-upon and culturally acceptable solutions. There are many examples of good management, such as the harvesting of trochus shells on only one day in Aitutaki, and the exclusion of fishing within the lagoons in Tokelau. The idea of marine sanctuaries and parks is also an excellent way of ensuring the maintenance of marine stocks in neighbouring areas.

The harvesting of trochus shells only on one day a year in Aitutaki lagoon meant that some adult stock and juveniles were allowed a year to spawn and grow. Minimum effort was expended and it was easy to identify anyone harvesting trochus out of season. Recently the harvest period has been extended and it will be interesting to find out the long-term effects.

Tokelau has maintained a closure on fishing within the lagoons. This has allowed a constant restocking on the ocean side, and the congregation of fish near out-flowing channels where a focused and sustainable fishery can be maintained. Lagoonal fish stocks are held in reserve against long periods of rough weather when fishing on the ocean side is not possible.

Subsistence fishing has always been in equilibrium so that catches were able to sustain the people. Windfall catches were normally distributed freely, and that in itself reduced the demand. It is a mistake, though, to think that subsistence fishing can be safely commercialised. The evidence shows that where this happens, increased catches are sold and the money is either accumulated as cash, dispersed for status, or even converted into capital investment in bigger vessels and equipment requiring larger catches, further stressing the fragile fish stock.

Development has brought widespread social changes, many of which can have indirect consequences for the marine environment. Population increases (despite heavy out migration), have increased 
demand, and as a consequence, severely affected and depleted fish stock. Urbanisation has also had the effect of concentrating the fishing of migrants in the neighbouring waters, which can rapidly become depleted and degraded. There are clear examples of this happening in Tuvalu and Vanuatu. The introduction of efficient new technologies such as scuba, hooker, netting and, on the industrial scale, superseiners, has created further over-exploitation problems. Solutions need to be culturally sound and then science can monitor the status of the stock and support rehabilitation rather than the other way round.

We have embraced certain elements of technological development with open arms and without any reserve or caution. This is in stark contrast to our thinking when we considered the development of tourism in 1950s and 1960s, when there was strong opposition, mainly due to fear of negative effects for our culture and traditions. High technology heavy engineering has been used to effect development and infrastructure projects with little thought to the broader environmental effects. Beach-mining and land reclamation is commonly and widely practiced without being screened by our traditional leaders. In many cases our leaders are the instigators. In many villages a blind eye is turned to destructive methods such as dynamiting, to the point of achieving a form of traditional acceptance.

Finally, I give the most tragic example relating to the harvesting of pearl and trochus shell and, most recently, bêche-de-mer. Harvesting was previously limited to free diving to allow for brood stock to survive at depth, preventing total depletion. However, in a study of a small group of islands in the western province of Solomon Islands it was found that the pearl and trochus stock was almost completely depleted down to a depth of over 70 metres. This was accomplished by hooker gear confiscated from apprehended Taiwanese clam boats and disposed of by public tender. The population involved was a migrant group which was at the end of a harvesting bonanza but fighting for survival. The ranks of the young divers were severely reduced by death and paralysis from bends, and there was an air of defiance and bravado by the few remaining divers to go deeper and for longer. The survival of the community was threatened.

In Fiji, the number of cases of death and disability from the use of hooker diving as well as scuba diving for bêche-de-mer has steeply increased, and the government is trying to do something about it. This 
is happening everywhere in the Pacific as the original sources become depleted and the prices of these items increase dramatically. We are paying for our resources with the lives of our young men. When our resources are finished the prices will continue to increase out of hand and we will have nothing to sell. Does it not make sense to limit our catch, save the lives of our most valuable resource, our young people, and benefit for ever?

Because of my involvement in the Forum Fisheries Agency and the South Pacific Applied Geoscience Commission, I am interested in regional cooperation in the marine sector. For a whole range of reasons, more cultural than economic, Pacific Island countries were able to mount a coordinated approach to oceanic fisheries development. They were able to put forward a very bold and resolute front against the plundering foreign fishing fleets of America and Asia. Control measures have been adopted in the form of licences with minimum terms and conditions, and a regional register of fishing vessels with a black-listing of renegades, and have increased licensing revenues. The negotiated US Treaty not only circumvented the United States Magnuson Act, which had legitimised the US fleet stealing our fish, but extracted very high rent and made the United States assume responsibility for the behaviour of its fleet. Destructive drift-net fishing was also halted, even though the fishing was almost entirely in the high seas.

The question that now needs to be asked is why these gains were not consolidated into regional licensing and controls. National selfinterest, self-assertion and pride must accept the responsibility. Some countries felt that they were worse off under regional arrangements despite receiving greater than five-fold returns under the US Treaty. Some made special arrangements with individual deep water fishing nations rather than sticking with the regional arrangements. The very same adversaries that the region had confronted were able to convince individual countries that it was in their national interest to accept bilateral arrangements which ended any hope of regional arrangements for the management and development of oceanic fisheries, the only truly shared resource. The real end to solidarity was that the countries with the fish felt that the others were there only for the ride. Little account was taken of the opportunity costs and the essential contribution of solidarity to establishing control over the fleets in the first place. 